\title{
Electrochemical Impedance Spectroscopy for Investigation on Ion Permeation in Thioctic Acid Self-Assembled Monolayer
}

\author{
Fupeng Zhi' ${ }^{1,2}$, Qian Ma1,2, Yanli Bai ${ }^{1,2}$, Shiqing $\mathbf{Q i}^{1,2}$ \\ ${ }^{1}$ National Nickel and Cobalt Advanced Materials Engineering Research Center, Lanzhou, China \\ ${ }^{2}$ Lanzhou Jinchuan Technology Park Co., Ltd., Lanzhou, China \\ Email: *zhifupeng@126.com
}

How to cite this paper: Zhi, F.P., Ma, Q., Bai, Y.L. and Qi, S.Q. (2019) Electrochemical Impedance Spectroscopy for Investigation on Ion Permeation in Thioctic Acid Self-Assembled Monolayer. Journal of Surface Engineered Materials and Advanced Technology, 9, 38-43.

https://doi.org/10.4236/jsemat.2019.93004

Received: June 16, 2019

Accepted: July 23, 2019

Published: July 26, 2019

Copyright $\odot 2019$ by author(s) and Scientific Research Publishing Inc. This work is licensed under the Creative Commons Attribution International License (CC BY 4.0).

http://creativecommons.org/licenses/by/4.0/

\begin{abstract}
Electrochemical impedance spectroscopy was employed to investigate the permeation of electrolyte ions in thioctic acid self-assembled monolayer when its structure was changed by the interaction of copper ions. The ion permeation was evaluated by using relatively low excitation frequencies, $0.2 \mathrm{~Hz}$ to $1000 \mathrm{~Hz}$, and quantified by an extra resistive component in the equivalent circuit $\left(\mathrm{R}_{\mathrm{SAM}}\right)$. The extent of ion permeation affected by the electrode potentials and the electrolyte concentration were investigated. The experimental results verified that $\mathrm{R}_{\mathrm{SAM}}$ decreased $\sim 70 \%$ by interaction with copper ions and that $\mathrm{R}_{\mathrm{SAM}}$ increased $\sim 2$ - 3 times when the electrolyte concentration was decreased by 10 times. This analysis can be performed without addition of redox species.
\end{abstract}

\section{Keywords}

Ion Permeation, Thioctic Acid, Self-Assembled Monolayer, Electrochemical Impedance Spectroscopy

\section{Introduction}

It is well known that electrochemical impedance spectroscopy (EIS) is an effective method to obtain some electrochemical information, involving charge transfer through redox groups within the SAM itself [1] [2] [3], the interfacial properties and double-layer phenomena [4] of modified electrodes at low overpotentials. For instance, SAMs modified with acid-base groups have been important for connecting double layer models with electrochemical theory and experiments [5]. EIS has also been extensively applied for direct or indirect detec- 
tion of chemical interactions at a self-assembled thiol-covered monolayer, with the aim of developing sensors and detectors [6] [7] [8]. Boubour and Lennox [9] [10] have investigated the importance of ion and solvent permeation into potential-induced defects in SAMs or reorganization of the thiols on the electrode surface. Gadzekpo and co-workers [11] have investigated the detection of metal ions using ion-channel sensor based on self-assembled monolayer of thioctic acid. The aim of this paper was to use EIS and relatively low excitation frequencies to study the permeation of electrolyte ions in thioctic acid self-assembled monolayer to structural change induced by interaction with copper ions.

In order to investigate the extent of ion permeation in carboxyl-base groups SAMs under different experimental conditions, thioctic acid monolayer was prepared. This monolayer could coordinate a number of copper ions. The organization of thioctic acid SAM was likely changed when copper ions were coordinated to the carboxyl groups. CV showed the blocking properties of the SAM were obviously decreased [11] [12]. An equivalent circuit in Figure 1, where $R_{S}$ represents the solution resistance and $C_{d l}$ the double layer capacitance, was sufficient to model the impedance data. The extra resistance will be used to describe the resistive properties of the SAMs and will for the semicircle be defined as $R_{S A M}$, the parallel resistance is denoted as $R_{3}$ to separate it from $R_{S A M} \cdot R_{3}$ describes the ease of moving ions from the interface to the SAM. For the thioctic acid monolayer in $\mathrm{KNO}_{3}$, the first parts of a semicircle were range from $2 \mathrm{~Hz}$ to $1000 \mathrm{~Hz}$, followed by the onset of a second semicircle down to $0.2 \mathrm{~Hz}$, as shown in Figure 2(a) and Figure 2(b). The average error of the fit obtained for each separate SAM in supporting electrolyte was below $10 \%$. Impedance spectra data were analyzed for thioctic acid monolayer in $0.1 \mathrm{~mol} / \mathrm{L} \mathrm{KNO}_{3}$ electrolyte in the potential range $0.05-0.40 \mathrm{~V}$ (vs $\mathrm{Ag} / \mathrm{AgCl}$ ). From the top curve in Figure 3(a), $\mathrm{R}_{\mathrm{SAM}}$ reached a minimum of almost $0.24 \mathrm{M} \Omega$ at $0.2 \mathrm{~V}$ and increased at more positive or negative potentials. The obvious change of $\mathrm{R}_{\mathrm{SAM}}$ indicated that some electrolyte ions were present due to the potential-induced defects in SAM. However, when copper ions were added to the electrolyte, $\mathrm{R}_{\mathrm{SAM}}$ decreased by $0.12-0.22 \mathrm{M} \Omega$ in the potential range $0.05-0.40 \mathrm{~V}$ (vs $\mathrm{Ag} / \mathrm{AgCl}$ ). The decreased resistance indicated that more electrolyte ions were present in the SAM. The change of $\mathrm{R}_{\mathrm{SAM}}$ with the potentials was slow after addition of copper ions to the electrolyte. This was most likely due to the thioctic acid self-assembled monolayer to structural change on the electrode surface when copper ions were coordinated to the carboxyl groups. Density-functional theory (DFT) calculations were also performed using the 3 - $21 \mathrm{G}$ basis set with Gaussian 03 program for the thioctic acid self-assembled monolayer and the thioctic acid self-assembled monolayer when copper ions were coordinated to the carboxyl groups. The obvious change of the bond lengths and bond angles showed the thioctic acid self-assembled monolayer to structural change on the electrode surface when copper ions were coordinated to the carboxyl groups. Of course, the negative charges on the carboxyl groups were also neutralized upon coordination, so this may also affect the extent of electrolyte ions permeation. It was verified that $R_{\text {SAM }}$ 


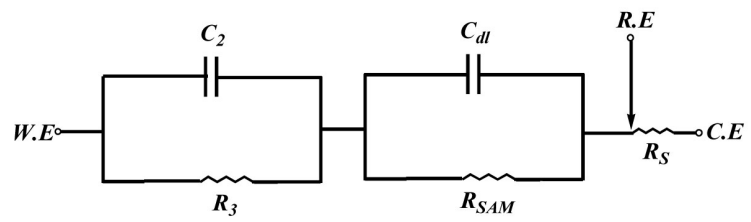

Figure 1. The equivalent circuit model was used to obtain equations for the impedance data. $R_{S}$ denotes the solution resistance, $C_{d l}$ the total double layer capacitance and $R_{S A M}$ was used to evaluate the ion permeation, $R_{3}$ describes the ease of moving ions from the interface to the SAM, $\mathrm{C}_{2}$ reflects the ability of the SAM to store ions. W.E is the working electrode, R.E is the reference electrode, and C.E is the counter electrode.

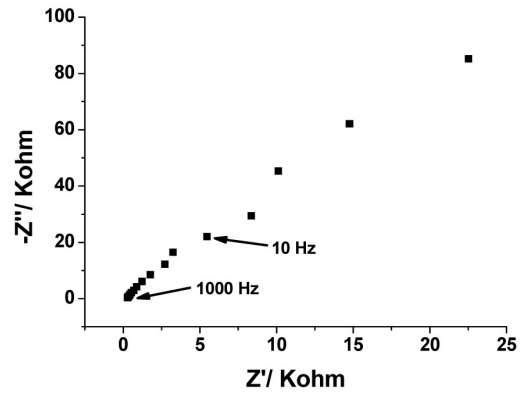

(a)

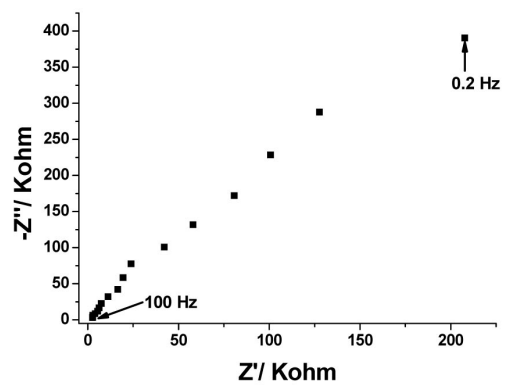

(b)

Figure 2. Impedance spectra obtained for the thioctic acid $\mathrm{SAM}$ in $\mathrm{KNO}_{3}$ at $0.05 \mathrm{~V}$. (a) $0.1 \mathrm{~mol} / \mathrm{L} \mathrm{KNO}_{3}$ and $2-1000 \mathrm{~Hz}$ and (b) $0.01 \mathrm{~mol} / \mathrm{L} \mathrm{KNO}_{3}$ and $0.2-100 \mathrm{~Hz}$, respectively.

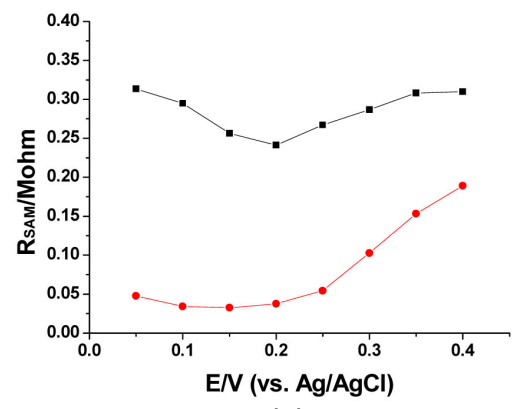

(a)

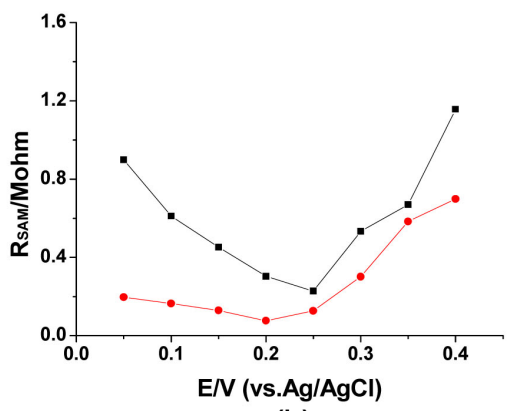

(b)

Figure 3. $\mathrm{R}_{\mathrm{SAM}}$ for the thioctic acid self-assembled monolayer as a function of the different potentials before ( and after $\left(\mathcal{)}\right.$ ) addition of $10^{-4} \mathrm{~mol} / \mathrm{L}$ copper ions. The electrolyte concentration and frequency range used for modeling were (a) $0.1 \mathrm{~mol} / \mathrm{L} \mathrm{KNO}_{3}$ and 2 $1000 \mathrm{~Hz}$ and (b) $0.01 \mathrm{~mol} / \mathrm{L} \mathrm{KNO}_{3}$ and $0.2-100 \mathrm{~Hz}$, respectively.

was related with the number of electrolyte ions, the same experiments were performed in $0.01 \mathrm{~mol} / \mathrm{L} \mathrm{KNO}_{3}$ electrolyte. The solution resistance $\left(\mathrm{R}_{\mathrm{S}}\right)$ was increased from $315 \Omega$ in $0.1 \mathrm{~mol} / \mathrm{L} \mathrm{KNO}_{3}$ to $3.3 \mathrm{~K} \Omega$ in $0.01 \mathrm{~mol} / \mathrm{L} \mathrm{KNO}_{3}$ electrolyte and, as expected, it also had a significant effect on the values of $\mathrm{R}_{\mathrm{SAM}}$, which were higher (Figure 3(b)). A consistent effect was observed from the different electrode potentials and the addition of copper ions. Interestingly, $\mathrm{R}_{\mathrm{SAM}}$ increased $\sim 2$ - 3 times when the supporting electrolyte concentration was decreased 10 times, revealing that $\mathrm{R}_{\mathrm{SAM}}$ does not evaluate directly with the electrolyte concentration. The effect was probably related to the ionic strength on the potential distribution at the interface. 
From Figure 3, the change of $\mathrm{R}_{\mathrm{SAM}}$ was obvious at different potentials, revealing the change of the number of electrolyte ions in the SAM. The large number of electrolyte ions was present in the SAM in the middle of potential range. The thioctic acid self-assembled monolayer to structural change on the electrode surface may also change with the different potentials [9] [10] [13]. The effect became more important above $0.25 \mathrm{~V}$, compared to the interaction with copper ions in Figure 3. A consisent phenomenon was observed from Figure 4, the change of $\mathrm{R}_{3}$ with the potential was parallel to $\mathrm{R}_{\mathrm{SAM}}$ in $0.01 \mathrm{~mol} / \mathrm{L} \mathrm{KNO}_{3}$ electrolyte. The change of $\mathrm{R}_{3}$ was also obvious above $0.25 \mathrm{~V}$, revealing the obvious ease of moving ions from the interface to the SAM. In a word, at potentials above $0.25 \mathrm{~V}$ in the $\mathrm{KNO}_{3}$ electrolyte (either 0.1 or $0.01 \mathrm{~mol} / \mathrm{L}$ ), the effect from the copper ions was no longer significant. An interesting phenomenon from Figure 3 and Figure 4 was also indicated that the relative effect from the electrode potential was lower when copper ions were coordinated to the carboxyl groups below $0.25 \mathrm{~V}$. This most likely reflected the fact that the carboxyl groups charges were neutralized and less able to change thiol organization on the surface. These experiments showed that the resistive properties of a carboxyl-base groups SAM can be significantly changed upon a chemical interaction. The presence of ions within the SAM was also affected by other factors, which may also bring important information. For example, a minimum in $\mathrm{R}_{\mathrm{SAM}}$ could also reveal the potential where the ionic conductivity within the monolayer is at maximum [13].

In conclusion, the extent of ion permeation affected by the different potential and the electrolyte concentration were investigated by electrochemical impedance spectroscopy and relatively low excitation frequencies. The ion permeation was evaluated by an extra resistive component in the equivalent circuit and was found to be affected by structural changes in the monolayer. It is obvious that the presence of electrolyte ions in the monolayer is an important factor to consider when the SAMs are investigated. Besides, it is an effective way to find the potential where the ionic conductivity within the monolayer is at maximum or minimum. An important advantage is that the experiments were conducted without any addition of redox species.

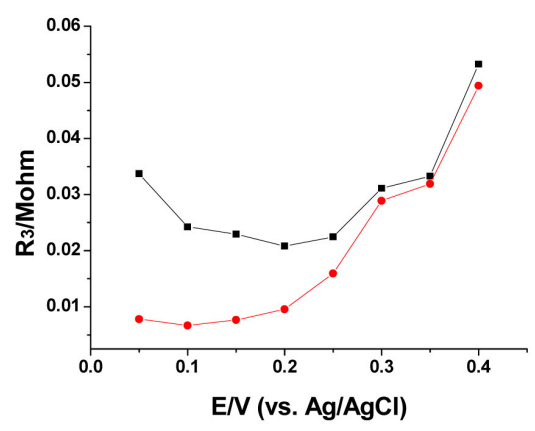

Figure 4. $\mathrm{R}_{3}$ for the thioctic acid self-assembled monolayer as a function of the different potentials before ( and after $(\mathbf{O})$ addition of $10^{-4} \mathrm{~mol} / \mathrm{L}$ copper ions. The electrolyte concentration and frequency range used for modeling were $0.01 \mathrm{~mol} / \mathrm{L} \mathrm{KNO}_{3}$ and 0.2 $100 \mathrm{~Hz}$, respectively. 


\section{Experimental}

\section{Self-assembly of thioctic acid monolayer on gold electrode}

After a gold electrode (Model CHI101, 2-mm diameter) was polished with alumina powder (diameter, 0.3 and $0.05 \mu \mathrm{m}$ ) and rinsed with pure water, this electrode was immersed for 3 mins in a hot "pirhana" solution (3:1 mixture of concentrated $\mathrm{H}_{2} \mathrm{SO}_{4}$ and $30 \% \mathrm{H}_{2} \mathrm{O}_{2}$ ). After copious rinsing with deionized water, the Au electrode was electrochemically cleaned by potential cycling in $0.5 \mathrm{~mol} / \mathrm{L}$ $\mathrm{H}_{2} \mathrm{SO}_{4}$ in the potential range of -0.20 and $1.60 \mathrm{~V}$ versus $\mathrm{Ag} / \mathrm{AgCl}$ at a scan rate of $10 \mathrm{mV} \cdot \mathrm{s}^{-1}$ for $20 \mathrm{mins}$ or until typical cyclic voltammogram of clean gold was obtained. After having been rinsed with distilled water, ethanol and having been dried with high purity nitrogen, then the electrode began to be modified. The modified electrode was obtained by immersion of the gold electrode in a 0.01 $\mathrm{mol} / \mathrm{L}$ ethanol solution of thioctic acid for a period of $6 \mathrm{~h}$ at room temperature.

Electrochemical impedance spectroscopy measurement

The thioctic acid SAM-coated gold electrode was used as the working electrode, a Pt wire as counter electrode and an $\mathrm{Ag} / \mathrm{AgCl}$ as reference electrode. All experiments were conducted at room temperature. Electrochemical impedance spectroscopy (EIS) measurements were carried out using VMP2 multi potentiostat (Princeton Applied Researcher, USA) and using an ac signal of $5 \mathrm{mV}$ amplitude at a frequency range of $0.2 \mathrm{~Hz}$ to $1000 \mathrm{~Hz}$. In order to investigate the effect from the different potential, the potential was varied between 0.05 and 0.40 $\mathrm{V}$ (vs $\mathrm{Ag} / \mathrm{AgCl}$ ). These potential limits were chosen to minimize the effect from faradaic currents (primarily reduction of dissolved oxygen and oxidation of the gold substrate). Experiment data were analyzed by ZSimpWin electrochemical software (Version 3.00, EChem Software, eDAQ Pty Ltd.). Addition of copper ions to the electrolyte (either 0.01 or $0.1 \mathrm{~mol} / \mathrm{L} \mathrm{KNO}_{3}$ ) to a final concentration of $10^{-4} \mathrm{~mol} / \mathrm{L}$ was made from an appropriate volume of $0.01 \mathrm{~mol} / \mathrm{L} \mathrm{CuCl}_{2}$ followed by manual stirring. The copper ion solution also contained $0.1 \mathrm{~mol} / \mathrm{L} \mathrm{KNO}_{3}$.

\section{Conflicts of Interest}

The authors declare no conflicts of interest regarding the publication of this paper.

\section{References}

[1] Calvente, J.J., Lopez-Perez, G., Ramirez, P., Fernandez, H., Zon, M.A., Mulder, W.H. and Andreu, R. (2005) Experimental Study of the Interplay between Long-Range Electron Transfer and Redox Probe Permeation at Self-Assembled Monolayers: Evidence for Potential-Induced Ion Gating. Journal of the American Chemical Society, 127, 6476-6486. https://doi.org/10.1021/ja050265j

[2] Sek, S., Misicka, A. and Bilewicz, R. (2000) Effect of Interchain Hydrogen Bonding on Electron Transfer through Alkanethiol Monolayers Containing Amide Bonds. The Journal of Physical Chemistry B, 104, 5399-5402. https://doi.org/10.1021/jp000376z

[3] Walter, D.G., Campbell, D.J. and Mirkin, C.A. (1999) Photon-Gated Electron Transfer 
in Two-Component Self-Assembled Monolayers. The Journal of Physical Chemistry $B, 103,402-405$. https://doi.org/10.1021/jp983460b

[4] Burshtain, D. and Mandler, D. (2004) Determination of the Heterogeneous Association Constants of Metal Ions to $\omega$-Mercaptoalkanoic Acids by Using Double-Layer Capacity Measurements. Chemphyschem, 5, 1532-1539. https://doi.org/10.1002/cphc.200400232

[5] Schweiss, R., Werner, C. and Knoll, W. (2003) Impedance Spectroscopy Studies of Interfacial Acid-Base Reactions of Self-Assembled Monolayers. Journal of Electroanalytical Chemistry, 540, 145-151. https://doi.org/10.1016/S0022-0728(02)01303-7

[6] Petoral, R.M., Björefors, F. and Uvdal, K. (2006) Metal Ion Interaction with Phosphorylated Tyrosine Analogue Monolayers on Gold. The Journal of Physical Chemistry $B, 110,23410-23416$. https://doi.org/10.1021/jp064075m

[7] Flink, S., van Veggel, F. and Reinhoudt, D.N. (2000) Sensor Functionalities in Self-Assembled Monolayers. Advanced Materials, 12, 1315-1328. https://doi.org/10.1002/1521-4095(200009)12:18<1315::AID-ADMA1315>3.0.CO;2-K

[8] Turyan, I. and Mandler, D. (1997) Selective Determination of Cr(VI) by a Self-Assembled Monolayer-Based Electrode. Analytical Chemistry, 69, 894-897. https://doi.org/10.1021/ac9607525

[9] Boubour, E. and Lennox, R.B. (2000) Stability of $\omega$-Functionalized Self-Assembled Monolayers as a Function of Applied Potential. Langmuir, 16, 7464-7470. https://doi.org/10.1021/la000514b

[10] Boubour, E. and Lennox, R.B. (2000) Potential-Induced Defects in n-Alkanethiol Self-Assembled Monolayers Monitored by Impedance Spectroscopy. The Journal of Physical Chemistry B, 104, 9004-9010. https://doi.org/10.1021/jp000151o

[11] Zugle, R., Kambo-Dorsa, J. and Gadzekpo, V.P.Y. (2003) Detection of Metal Ions Using Ion-Channel Sensor Based on Self-Assembled Monolayer of Thioctic Acid. Talanta, 61, 837-848. https://doi.org/10.1016/S0039-9140(03)00377-1

[12] Lu, X.Q., Li, M.R., Yang, C.H., Zhang, L.M., Li, Y.F., Jiang, L., Li, H.X., Jiang, L., Liu, C.M. and Hu, W.P. (2006) Electron Transport through a Self-Assembled Monolayer of Thiol-End-Functionalized Tetraphenylporphines and Metal Tetraphenylporphines. Langmuir, 22, 3035-3039. https://doi.org/10.1021/la0520511

[13] Protsailo, L.V. and Fawcett, W.R. (2002) Electrochemical Impedance Spectroscopy at Alkanethiol-Coated Gold in Propylene Carbonate. Langmuir, 18, 8933-8941. https://doi.org/10.1021/la0201218 